\title{
Micropollutants in the Sediment of the SaiGon-DongNai River: Situation and Ecological Risks
}

\author{
Mai Tuan Anh ${ }^{\mathrm{a}, \mathrm{b}^{\star}}$, Lan Chi Do Honga, Ngoc Vinh Nguyen ${ }^{\mathrm{a}}$, Cam Loan Tu Thi ${ }^{\mathrm{a}}$, Triet Lam Minha, \\ Kristin Becker-Van Slooten ${ }^{\mathrm{b}}$, and Joseph Tarradellas ${ }^{\mathrm{b}}$
}

\begin{abstract}
This study is dedicated to the monitoring of environmental pollution in the SaiGon-DongNai (SGDN) river basin using ecotoxicological tests recently developed by the Institute for Environment and Resources (IER-CEFINEA). This paper presents the results of the analysis of micropollutants (pesticides and heavy metals); it also considers the effects of such pollutants on ecosystems. Results show that SGDN river sediments are contaminated by industrial and agricultural effluents. Although the pollution level does not exceed the probable effect level (PEL) value, SGDN sediments appear to have reached a toxicity level that should be monitored.
\end{abstract}

Keywords: Ecotoxicity tests $\cdot$ Heavy metals $\cdot$ Pesticides $\cdot$ SaiGon-DongNai river $\cdot$ Sediment quality

\section{Introduction}

The SaiGon-DongNai (SGDN) river plays a very important role for the social and economic development of the eleven provinces that depend upon its basin. Among them: the Southern Principal Economic Zone (SPEZ), which includes Hochiminh City, Binh Duong, DongNai, and Ba Ria-Vung Tau Provinces. The river is one of the main sources of water supply for nearly 7 million residents living downstream, in Hochiminh City, Bien Hoa City, and ThuDauMot Town [1-3].

With a current population of 15 million inhabitants, the basin is experiencing a fast and highly complex development. The river is used for different purposes and a large amount of toxic waste is discharged into it

\footnotetext{
${ }^{*}$ Correspondence: Dr. M.T. Anh ${ }^{\mathrm{a}, \mathrm{b}}$

alnstitute for Environment and Resources (CEFINEA) VietNam National University of Hochiminh City 142 To Hien Thanh St., Dist. 10, HCMC, VN E-Mail: mtanh@hotmail.com

bLaboratory of Environmental Chemistry and Ecotoxicology (CECOTOX)

ENAC-ISTE, Bat. GR

Swiss Federal Institute of Technology (EPFL)

$\mathrm{CH}-1015$ Lausanne

Tel.: + 41216932763

Fax: + 41216935760

E-Mail: mai.tuananh@epfl.ch
}

daily, strongly affecting the stock and quality of water, as well as the biodiversity of the SGDN river. The new urban, resident and industrial zones established along the river banks - from the upstream area of LamDong, BinhThuan, BinhPhuoc, TayNinh Provinces to the downstream area of Hochiminh City through DongNai and BinhDuong Provinces, are the main sources of river pollution [1][4-6].

Within the framework of the cooperation program established between the CECOTOX (EPFL) and IER-CEFINEA (VNU-HCMC), a pilot project has been set up aimed at assessing the level of river pollution. Sediment samples have been analyzed at CEFINEA and it has been found that they are contaminated with pathogens, nutrients, metals, and organic chemicals. These pollutants tend to sorb onto both inorganic and organic materials that then settle in deposit areas. In large waterways, sediments may accumulate huge quantities of contaminants.

The disruptive action of contaminated sediments on ecosystems is well documented and this study intends to focus on the disruptive effects caused by pesticides and heavy metals (HM), contamination levels and toxicity effects.

The obtained results describe the contamination of the SGDN river by micropollutants and its influence on the river ecosystem.

\section{Materials and Methods}

A total of ten sampling sites along SGDN river have been chosen, with five sites in the SaiGon river and 5 sites in the DongNai river (Fig. 1). Sediments were taken every three months between November 1997 and December 1998, always at low tide.

The rice field water and soil samples were taken from an intensive agricultural zone at BinhMy Village - CuChi District Hochiminh City between November 1999 and June 2000.

Surface sediments were sampled with an Eckman grab. For each site, sediments were taken from three points: near the two banks and in the center of the waterway. Samples were put into a clean aluminum box (for pesticide analysis) and plastic bag (for heavy metal analysis) and stored at $4{ }^{\circ} \mathrm{C}$ during transport. In the laboratory, a composite sample was prepared by mixing in the same proportions the three samples for each sampling site. This was then dried at room temperature for about 5 to $10 \mathrm{~d}$. Dried samples were crushed into powder using a ceramic mortar and then sifted through a $1 \times 1 \mathrm{~mm}$ sieve. Samples were stored in a brown glass flask at $4{ }^{\circ} \mathrm{C}$ until analysis.

\section{Pesticide Analysis Method}

$10 \mathrm{~g}$ of dried sediment were extracted with ultrasound with a mixture of ace- 


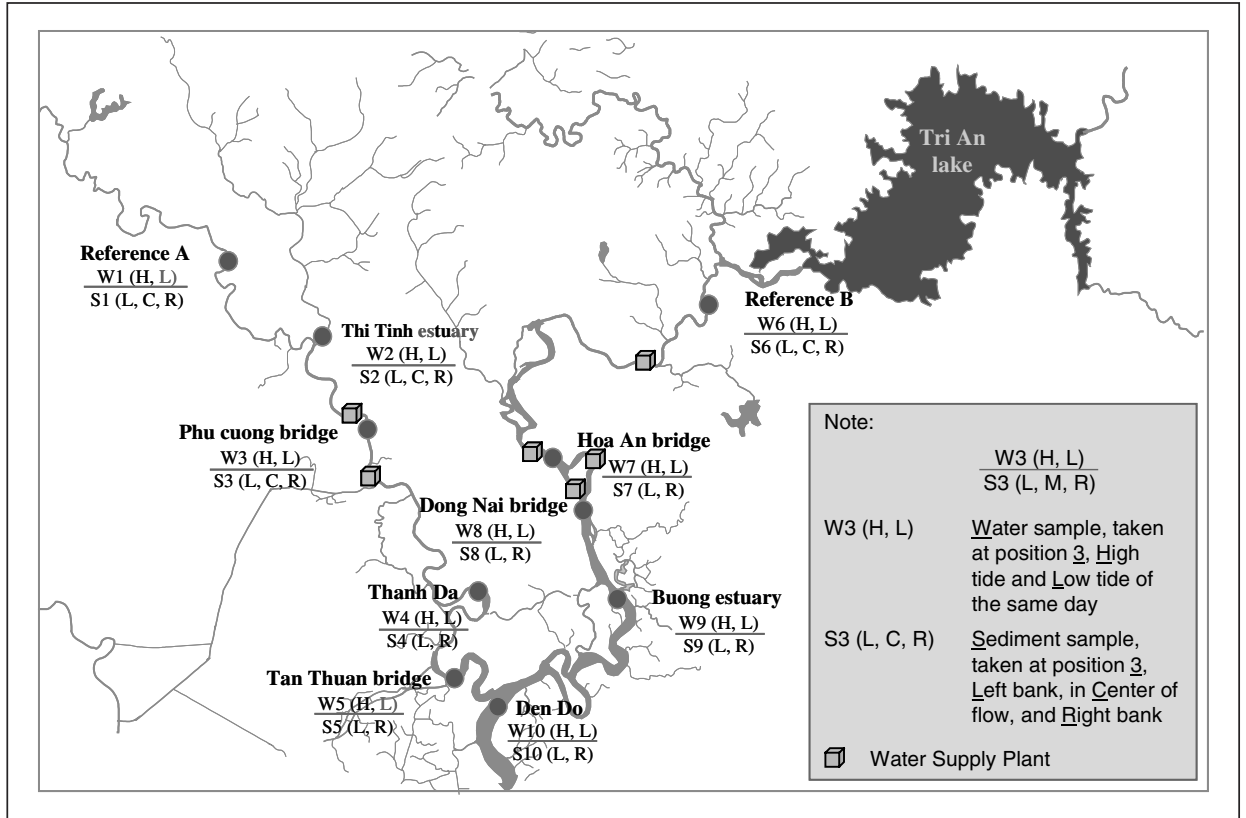

Fig. 1. Sampling site map

tone/DCM 1:1. The organic phase was dried using anhydrous $\mathrm{Na}_{2} \mathrm{SO}_{4}$, then concentrated and extracted into hexane. The extract was purified using a florisil chromatographic column. The elution was done with $20 \mathrm{ml}$ of hexane (fraction a), $30 \mathrm{ml}$ of hexane/ether $1: 1$ (fraction b) and $40 \mathrm{ml}$ of hexane/ether 85:15 (fraction c). Fractions b and c were combined and purified with $1 \mathrm{~g} \mathrm{Cu}$ powder to eliminate the sulphur content in the samples. The final extract was dissolved in iso-octane and concentrated by nitrogen flow. The extract was analyzed by GC/ECD (for organochlorines) and GC/FPD (for organophosphorus) using a GC Perkin Elmer AutoSystem XL, column SPB-5 (30 $\mathrm{m} \times 0.25 \mathrm{~mm} \times 0.25 \mu \mathrm{m})$, carrier gas $\mathrm{N}_{2}$.

\section{Heavy Metal Analysis Method}

About $5 \mathrm{~g}$ of dried sediment were digested during one night at reflux with $50 \mathrm{ml}$ aqua regia ( $\mathrm{HCl}$ conc./ $\mathrm{HNO}_{3}$ conc. 3:1). The extract was cooled, filtered through a cellulose filter, and concentrated to about $20 \mathrm{ml}$ on a stove. The extract was filtered again into a $50 \mathrm{ml}$ graduated flask and diluted to the mark. Each element of the extracted solution was analyzed by AAS under standard conditions, using a Perkin Elmer Atomic Absorption Spectrophotometer Analyst-300.

\section{Toxicity Test Method}

Dried sediments and soils were extracted with dichloromethane (DCM) (organic extraction) or with bidistilled water (aqueous extraction) as described below:

\section{Organic Extraction}

Approximately $20 \mathrm{~g}$ of dried sediment or soil and $20 \mathrm{ml}$ of liquid material (water or wastewater) were extracted using $150 \mathrm{ml}$ of DCM followed by agitation for $6 \mathrm{~h}$ with an end-to-end agitator at 200-300 rpm. After decantation, the supernatant was filtered using anhydrous $\mathrm{Na}_{2} \mathrm{SO}_{4}$. The DCM was concentrated with a Rotavapor $\left(30^{\circ} \mathrm{C}, 150\right.$ Torr $/ \mathrm{mmHg}$ ) to $1 \mathrm{ml}$. Three $\mathrm{ml}$ of dimethyl sulfoxide (DMSO) were added, and the remaining DCM was evaporated. Glassware was cleaned with acetone and hexane prior to use.

\section{Aqueous Extraction}

Dried sediments or soils were extracted with bidistilled water by mixing the sediment and water in the proportion 1:4 (w/v) in a centrifugation tube. After shaking for $2 \mathrm{~h}$ with an end-to-end agitator at 200-300 rpm, the samples were centrifuged at 2000 rpm for $10 \mathrm{~min}$. The supernatant was used for toxicity assays. Although centrifugation may change the toxicity of aqueous extracts because of changes in redox potential, it is a well-accepted and documented method for obtaining aqueous extracts.

After extraction, extracts were tested with three different organisms: Ceriodaphnia cornuta, Daphnia magna, and Vibrio fischeri following ISO 1998 and OECD protocols. Water samples were tested directly on test organisms [7-9].

\section{Results and Discussion}

\section{Micropollutant Level}

Minimum and maximum detected organochlorine (OC) concentrations in SGDN river sediments are presented in Table 1. Calculations of concentrations have been based on dry weights (values corrected for recovery and water content, expressed in $\mu \mathrm{g} / \mathrm{kg}$ dry weight).

Quality control was ensured by analyzing certified sediment SRM 1941a from the

Table 1. Organochlorine concentration ( $\mu \mathrm{g} / \mathrm{kg}$ dry weight) in SGDN sediment

\begin{tabular}{|c|c|c|c|c|c|c|c|c|c|}
\hline Site & $\alpha-\mathrm{BHC}$ & $\beta-\mathrm{BHC}$ & $\gamma-\mathrm{BHC}$ & $\delta-\mathrm{BHC}$ & Heptachlor & $\begin{array}{l}\text { Hept. } \\
\text { Epoxide }\end{array}$ & pp'-DDE & pp'-DDD & pp'-DDT \\
\hline s1 & ND-0.95 & ND-1.03 & ND-0.44 & ND-2.28 & ND -1.44 & ND & $2.43-2.78$ & $0.67-1.52$ & ND-1.15 \\
\hline S2 & ND-0.57 & ND-0.91 & ND-0.36 & ND-6.09 & ND -0.93 & ND & $2.68-5.47$ & $0.93-3.30$ & ND-0.83 \\
\hline S3 & ND-0.37 & ND-0.57 & ND-0.31 & ND-3.73 & ND -0.59 & ND & $2.54-5.47$ & $0.83-4.55$ & $0.42-1.85$ \\
\hline S4 & ND-0.64 & ND-0.81 & ND-0.33 & ND-6.77 & ND-1.08 & ND & $2.32-3.47$ & $1.27-3.60$ & ND-0.96 \\
\hline S5 & ND-0.62 & ND-1.59 & ND-0.38 & ND-8.46 & ND-1.19 & ND & $3.73-4.51$ & $5.27-10.46$ & $0.42-4.40$ \\
\hline S6 & ND-0.45 & ND-1.16 & ND-0.43 & ND-4.70 & ND- 0.78 & ND & $0.99-2.05$ & ND-1.43 & ND-1.09 \\
\hline S7 & ND-0.79 & ND-0.79 & ND-0.38 & ND-10.98 & $0.22-4.03$ & ND & $3.57-4.95$ & $0.07-3.50$ & ND-7.72 \\
\hline S8 & ND-0.65 & ND-1.81 & ND-0.33 & ND-5.75 & ND-1.52 & ND & $2.35-4.17$ & $1.07-2.39$ & ND-1.94 \\
\hline s9 & ND-0.66 & ND-1.26 & ND- 0.45 & ND-8.12 & ND-0.95 & ND & $2.28-2.71$ & $0.82-2.81$ & ND-6.30 \\
\hline S10 & ND-0.63 & ND-0.93 & ND-0.36 & ND-4.46 & ND-1.63 & ND & $0.52-1.21$ & $1.04-3.64$ & ND-0.84 \\
\hline TEL & - & - & 0.94 & - & - & 0.6 & 1.42 & 3.54 & 1.19 \\
\hline PEL & - & - & 1.38 & - & - & 2.74 & 6.75 & 8.51 & 4.77 \\
\hline
\end{tabular}


National Institute of Standard and Technology - NIST. SRM-1941a was analyzed three times and average recovery varied from $84 \%$ to $117 \%$. Every sample was analyzed a minimum of three times.

As shown in Table 1, organochlorine concentrations in SGDN sediments are low except for $\delta$-BHC. The relatively high concentrations of $\delta$-BHC can be explained by the fact that during the dry season, the river flow is small and crops are heavily sprayed with pesticides.

Compared to other sites, S7 shows high values for maximum concentrations of $\delta$-BHC and heptachlor. Strongly contaminated by effluents from upstream industrial zones such as Amata, BienHoa I, BienHoa II, S7 is located near HoaAn Bridge, next to Hochiminh's and BienHoa's water supply stations; it must therefore be carefully monitored.

Assessments were made based on TEL (Threshold Effect Level) and PEL (Probable Effect Level) values [10-13]. Fig. 2 and 3 display normalized concentrations of the ratio between highest concentrations of individual organochlorine and TEL or PEL value respectively.

Pollutants of the DDT group have been detected in most sites for all sampling events. Their concentrations exceeded TEL values at several sites, especially at sites S3, S5 and S7. Although the use of DDT in Vietnam was limited in the eighties and prohibited for agriculture since 1991 [14], it can still be found in the environment due to its persistence and the difficulty to control its use. The concentration of DDT in SGDN sediments varied depending on location and time of sampling.

DDT was detected in very low concentrations at sites S1 and S6. These sites were considered as reference sites, since no agricultural activity has been reported in a range of $10 \mathrm{~km}$.

Furthermore, results show that concentrations of $\gamma$-BHC reach only half of the threshold effect level. Concentrations of $\delta$-BHC, however, are 5 to 20 times larger than concentrations of $\gamma$-BHC, but $\delta$-BHC has fewer disruptive endocrine effects.

Fig. 3 shows that the highest detected concentrations of pp'-DDT at sites S5, S7 and $\mathrm{S} 9$ are above the PEL value. As mentioned above, the presence of pollutants at site $\mathrm{S} 7$ is an issue and concentrations have to be monitored on a regular basis.

Organophosphorus (OP) compounds were not detected in any soil and sediment samples, but diazinon, a commonly-used pesticide, was found in the rice-field water samples of BinhMy Village. Because OP pollutants do not last long as they are rapidly degraded once in the environment,

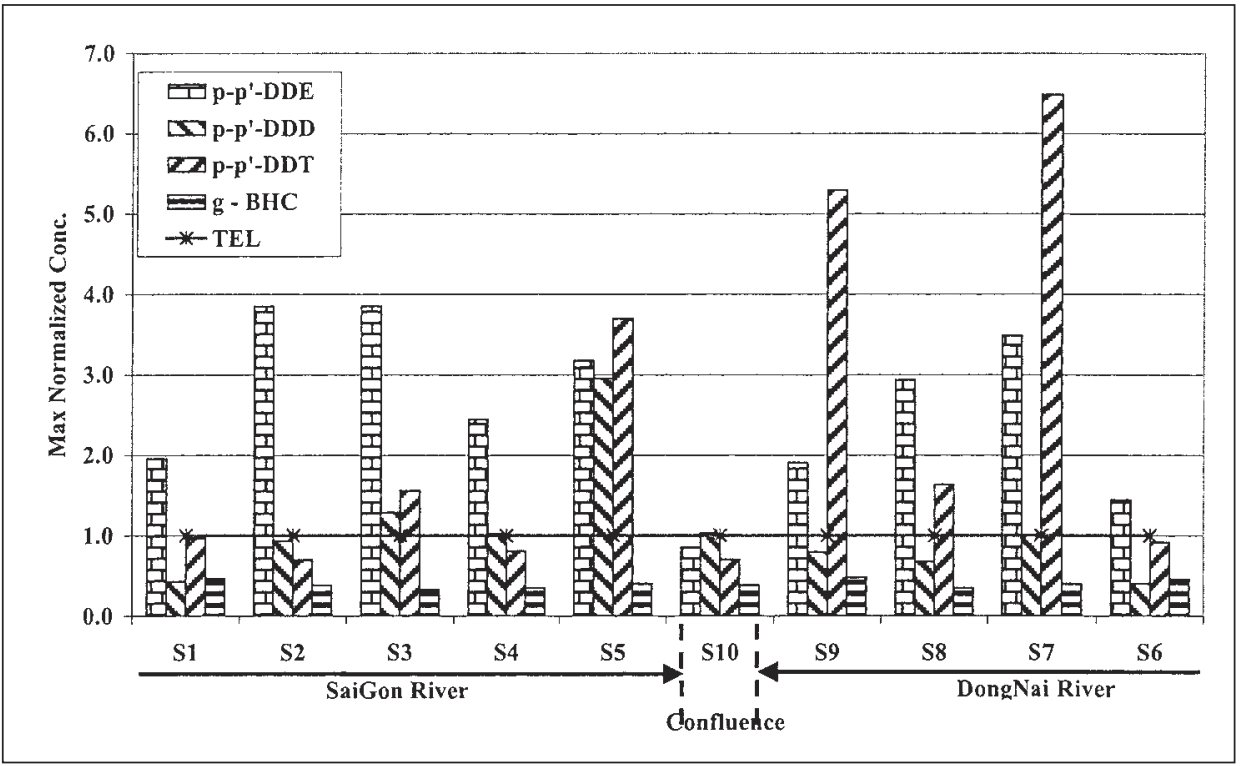

Fig. 2. Comparison between maximum $O C$ detected concentrations and TEL values

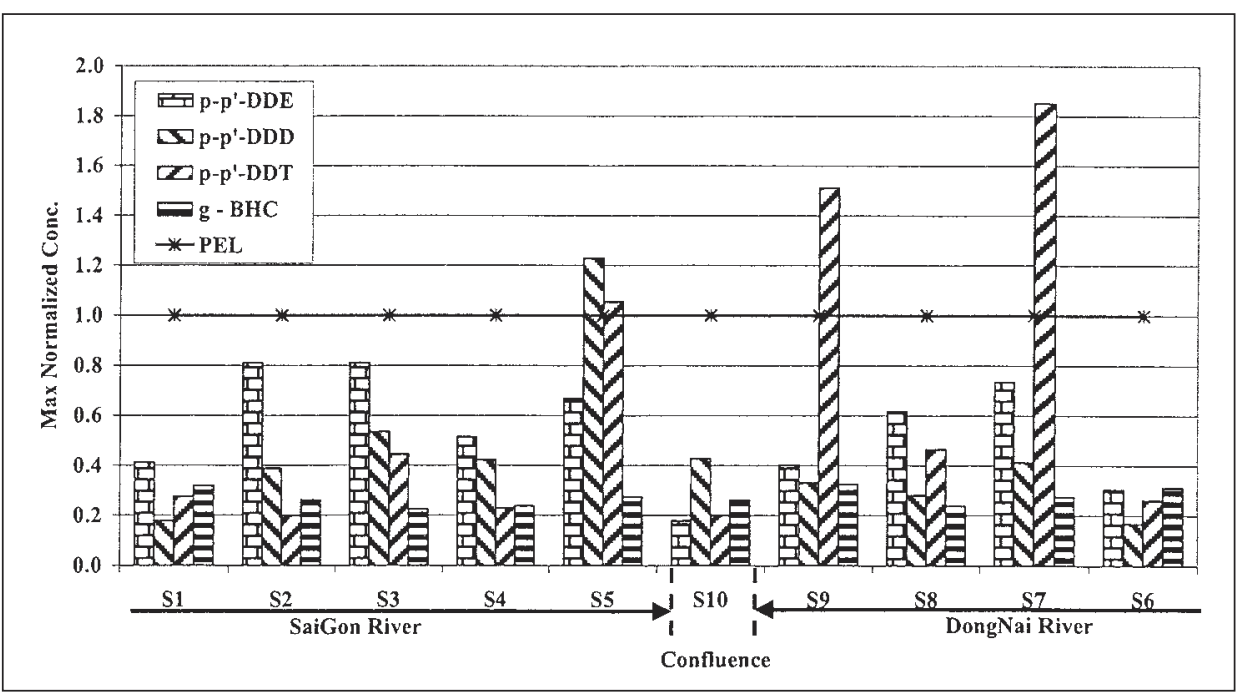

Fig. 3. Comparison between maximum OC detected concentrations and PEL values

sampling time must be chosen carefully (usually $1-3 \mathrm{~d}$ after spraying). Diazinon concentrations measured in samples of rice-field water are shown in Table 2.

Table 2. Diazinon concentration $(\mu \mathrm{g} / \mathrm{l})$ in rice field water in function of time once sprayed

\begin{tabular}{|ccc|}
\hline \multicolumn{3}{|c}{ Days } \\
1 & 3 & 10 \\
1262.72 & 111.44 & ND \\
ND: Non-Detectable &
\end{tabular}

Diazinon concentrations measured $1-3 \mathrm{~d}$ after spraying were rather high in comparison with the $\mathrm{LC}_{50}$ value given in the literature for most aquatic organisms [15] (Table 3). Ten days after spraying, diazinon was degraded and thus not detected anymore.
Heavy metal (HM) contamination levels in SGDN river sediment are presented in Table 4.

In Fig. 4 and 5, normalized concentrations of HM (the ratio between the mean concentration of individual $\mathrm{HM}$ and the TEL and PEL values respectively) have been used to assess contamination levels [13][16-20]. The presence of HM in SGDN river sediments is mainly due to industrial and agricultural activities in the basin. Fig. 4 and 5 show that concentrations of HM are close to the TEL values and still below the PEL values (except for $\mathrm{Ni}$ and $\mathrm{Cr}$ ). The unusually high concentrations at some upstream sites are not understood yet; they could be due to local mining activities.

Data from HCMC canal sediments provide information on the contamination level of the city. Previously published data [21] are compared with our data in Table 5. 
Table 3. $\mathrm{LC}_{50}-96 \mathrm{~h}$ of diazinon for aquatic organisms

$\begin{array}{lc}\text { Specie } & \mathrm{LC}_{50}(\mu \mathrm{g} / \mathrm{l}) \\ \text { Pteronarcys california (Stonefly) } & 25 \\ \text { Gammarus fasciatus (amphipod) } & 0.2 \\ \text { Pimephales promelas (fathead minnow) } & 6970 \\ \text { Lepomis macrochirus (bluegill) } & 168 \\ \text { Oncorhynchus mykiss (rainbow trout) } & 90\end{array}$

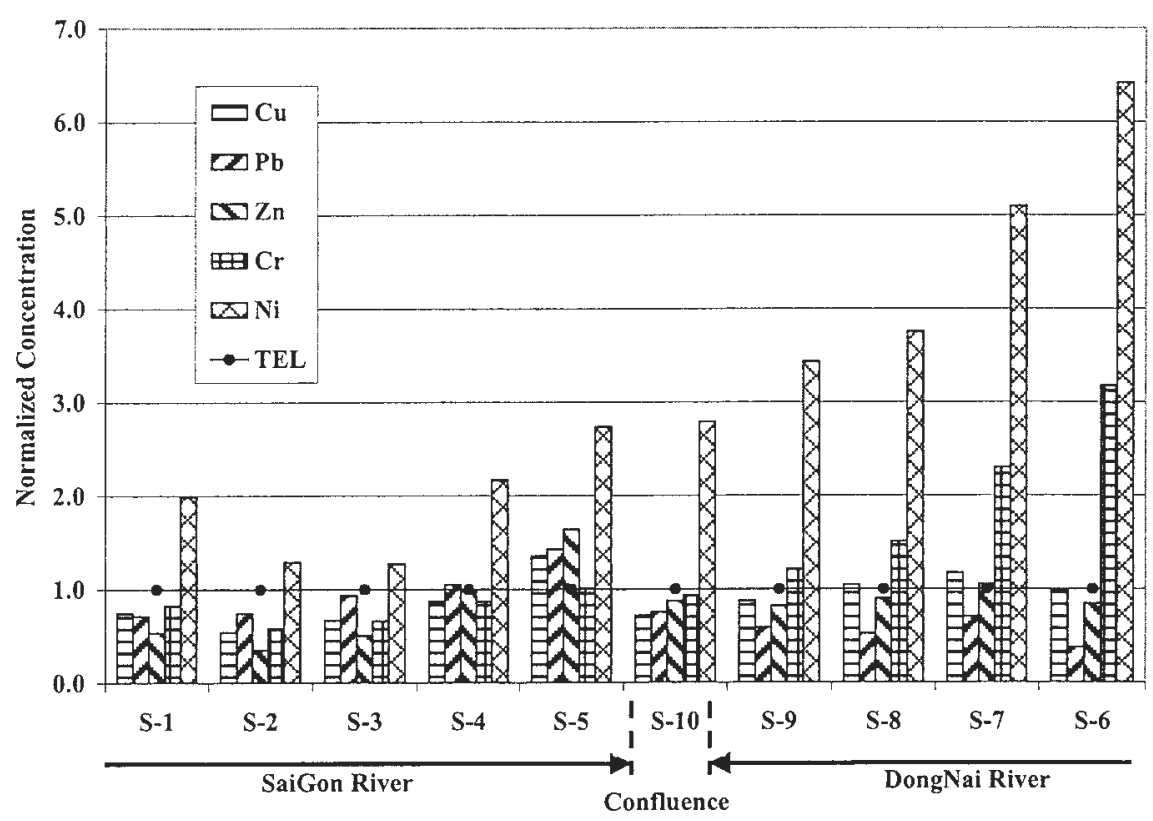

Fig. 4. Comparison between mean HM concentrations and TEL values

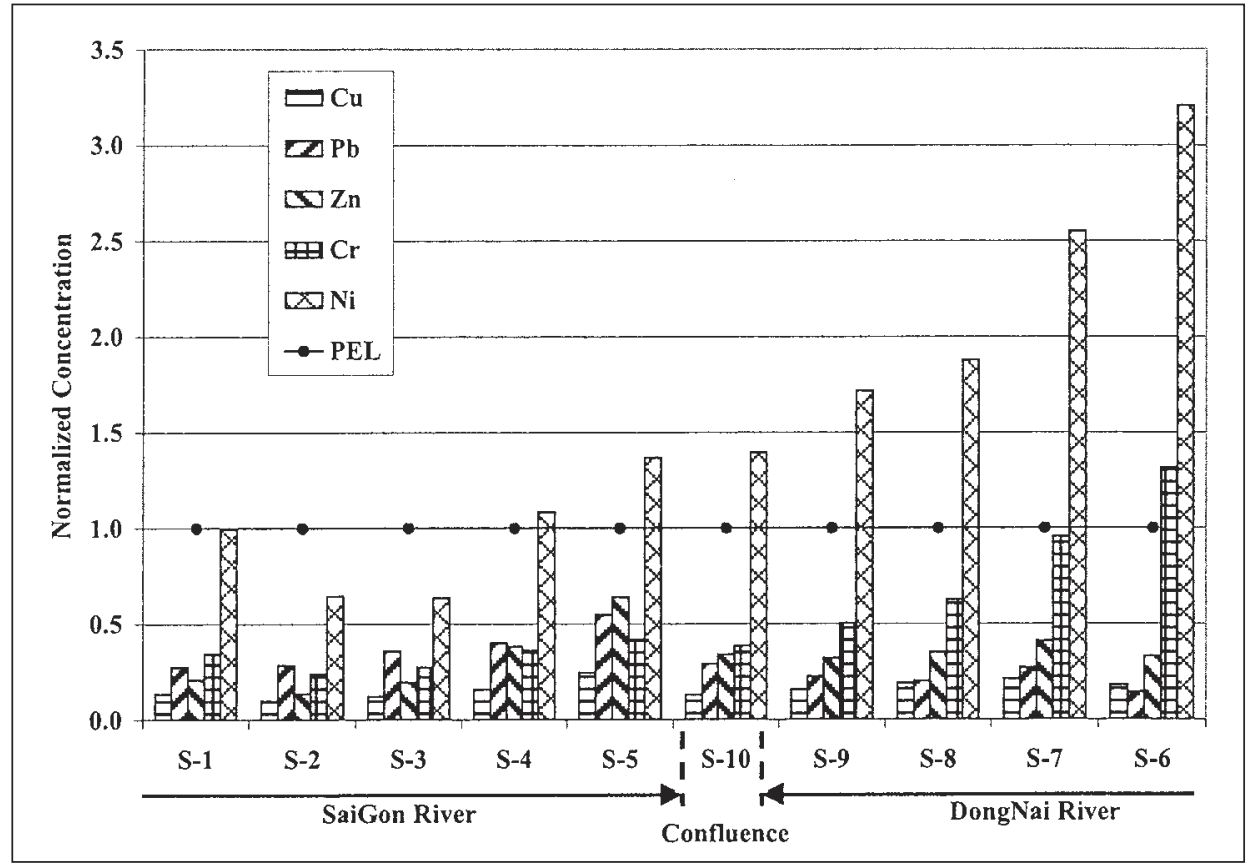

Fig. 5. Comparison between mean HM concentrations and PEL values
Table 4. Mean values for heavy metal concentrations $(\mathrm{mg} / \mathrm{kg} \mathrm{dry}$ weight) in SGDN sediments

$\begin{array}{lrrrrr} & \mathrm{Cu} & \mathrm{Pb} & \mathrm{Zn} & \mathrm{Cr} & \mathrm{Ni} \\ \text { S-1 } & 26.53 & 25.02 & 65.97 & 30.87 & 35.88 \\ \text { S-2 } & 19.38 & 26.1 & 43.38 & 21.61 & 23.22 \\ \text { S-3 } & 23.86 & 32.72 & 62.07 & 24.58 & 22.86 \\ \text { S-4 } & 30.96 & 36.68 & 120.16 & 32.44 & 39.01 \\ \text { S-5 } & 48.41 & 49.89 & 201.74 & 37.73 & 49.23 \\ \text { S-6 } & 35.32 & 13.15 & 103.76 & 118.3 & 115.45 \\ \text { S-7 } & 41.89 & 24.68 & 129.04 & 85.87 & 91.8 \\ \text { S-8 } & 37.31 & 18.35 & 110.71 & 56.33 & 67.63 \\ \text { S-9 } & 31.12 & 20.65 & 100.95 & 45.27 & 61.79 \\ \text { S-10 } & 25.58 & 26.43 & 107.4 & 34.69 & 50.22 \\ \text { Mean } & 32.04 & 27.37 & 104.52 & 48.77 & 55.71 \\ \text { TEL } & 35.7 & 35 & 123 & 37.3 & 18 \\ \text { PEL } & 197 & 91.3 & 315 & 90 & 36\end{array}$

Table 5 shows that DDT contamination levels in the city's canal sediments are about 10 times higher than in SGDN river sediments. Contamination levels of HM are also 3 to 6 times higher within the city than in the countryside. Thus, it appears that the city's canal sediments act as reservoirs of toxic materials, strongly affecting the SGDN water and sediment quality, amplified by tidal effects (most of the SGDN river basin is located in the semi-tidal zone).

\section{Toxicity Tests}

The first matrix was sediment from the SaiGon-DongNai river. Sediments act as a sink for contaminants and as sources of pollution for ecosystems. If loadings of these contaminants into waterways are large enough, sediments may accumulate excessive quantities of pollutants that directly and indirectly disrupt ecosystems, causing significant contamination and loss of biodiversity. There have been many studies that document the importance of sediment contamination on ecosystem quality and the widespread incidence of sediment contamination.

The second and third matrices were selected rice-field water and soil samples, which are representative of typical agricultural activities in the region. Farmers are encouraged to increase rice production, but there is no control of the use of cheap and hazardous pesticides. Furthermore, pest management is not sufficiently and properly carried out.

The fourth and fifth matrices were industrial and domestic wastewaters that are representative of the recent development of domestic and industrial activities. Environmental problems are dramatically increasing due to a lack of wastewater treatment.

Toxicity tests were undertaken by exposing three aquatic organisms (Daphnia magna, Vibrio fischeri, and Ceriodaphnia cornuta, an autochthonous daphnid) to the 
Table 5. Concentrations of micropollutant inside and outside HCMC

\begin{tabular}{|c|c|c|c|c|c|c|c|}
\hline & $\begin{array}{l}\text { pp'- } \\
\text { DDE }\end{array}$ & $\begin{array}{l}\text { pp'- } \\
\text { DDD }\end{array}$ & $\begin{array}{l}\text { pp'- } \\
\text { DDT }\end{array}$ & $\mathrm{Cr}$ & $\mathrm{Cu}$ & $\mathrm{Pb}$ & $\mathrm{Zn}$ \\
\hline SG-DG River Sediment & $\begin{array}{c}\mu \mathrm{g} / \mathrm{kg} \\
3.68^{\mathrm{a}}\end{array}$ & $\begin{array}{c}\mu \mathrm{g} / \mathrm{kg} \\
3.72^{\mathrm{a}}\end{array}$ & $\begin{array}{c}\mu \mathrm{g} / \mathrm{kg} \\
2.71^{\mathrm{a}}\end{array}$ & $\begin{array}{c}\mu \mathrm{g} / \mathrm{kg} \\
48.8^{\mathrm{b}}\end{array}$ & $\begin{array}{l}\mu \mathrm{g} / \mathrm{kg} \\
32.0^{\mathrm{b}}\end{array}$ & $\begin{array}{l}\mu \mathrm{g} / \mathrm{kg} \\
27.4^{\mathrm{b}}\end{array}$ & $\begin{array}{c}\mu \mathrm{g} / \mathrm{kg} \\
104.5^{\mathrm{b}}\end{array}$ \\
\hline HCMC Canal Sediment & $29.1^{c}$ & $27.8^{\mathrm{c}}$ & $23.0^{c}$ & $261.8^{c}$ & $99.2^{c}$ & $119.3^{c}$ & $442.3^{c}$ \\
\hline
\end{tabular}

different samples. For the water matrix, test organisms were directly exposed to the samples and in addition to their organic extracts. But the application of toxicity tests to solid samples involved two independent steps: (i) the desorption of contaminants originally adsorbed to the soil or sediment particles into a liquid phase (aqueous extractions and organic solvent extractions) and (ii) the exposure of tested organisms to the extracts. The composition of extracts thus depends on the properties of soil or sediment, the properties of contaminants involved and on the conditions of the extraction procedure.

The high number of ecotoxicity tests carried out (86 samples and extracts $\times 7 \mathrm{ex}$ posure times of 3 experimental organisms $=602$ ecotoxicity test results) enabled us to establish a classification of the toxicity [22] as shown in Fig. 6, which summarizes and illustrates the toxicity observed in the different matrices.

The results show an acute toxicity of the extracts from most samples of the SaiGon-DongNai river system and of rice fields. Furthermore, we are also concerned with a potential chronic toxicity that should be studied in the future. As mentioned

above, sediments act both as a sink and reservoir for persistent contaminants, influencing the fate and concentration of pollutants, and potentially damaging aquatic ecosystems. Our results indicate serious environmental problems in the studied basin around HCMC due to heavy pollution from industrialization, urbanization and the over-use of agrochemicals in rice fields. Improved environmental management is urgently needed.

\section{Acknowledgements}

We wish to thank the Swiss Agency for Development and Cooperation (SDC) for its financial support that enabled us to carry out this study.

Received: July 5, 2003

[1] L.M. Triet, N.T. Hung, M.T. Anh, 'Final Report: Study and Set up of the Scientific Base serving for Integrated Management for SaiGon-DongNai Water Source', National Project KH-01.17, HaNoi, 2000.

[2] CEFINEA - CECOTOX, 'Final Report: Study on Pesticide and Heavy Metal in Water and Sediment of SaiGon-DongNai River', Pilot Project, HCMC, 2000.

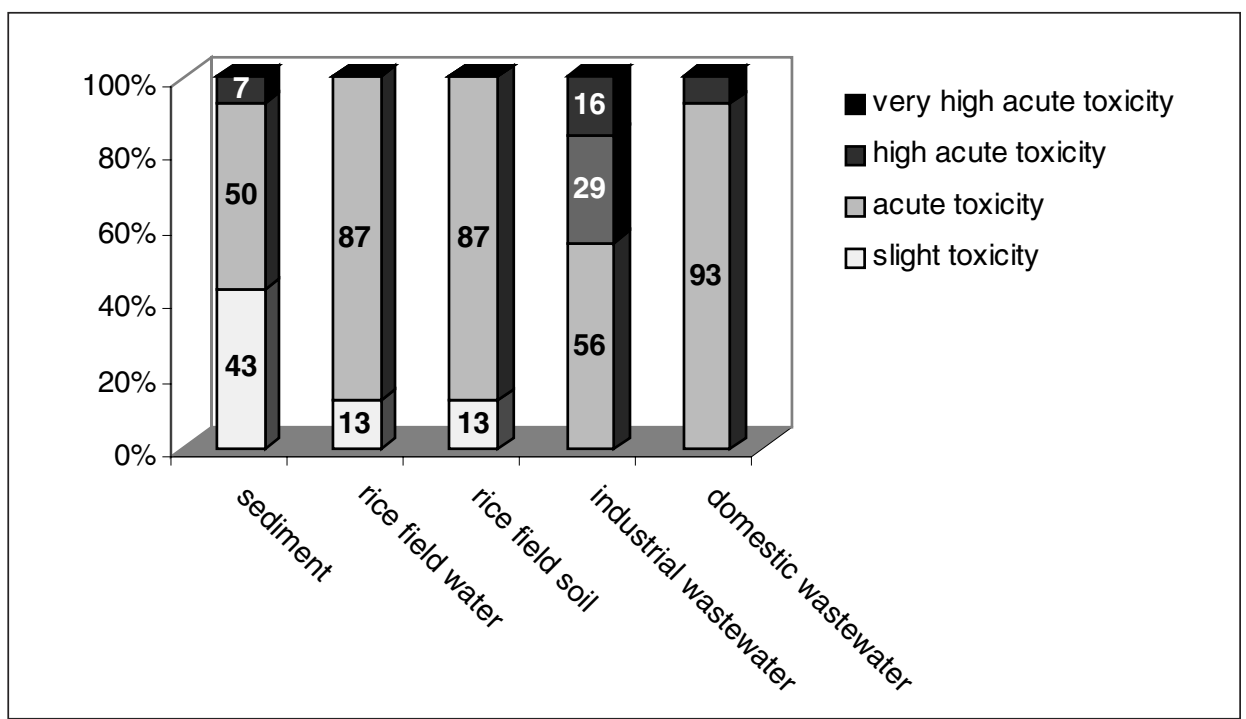

Fig. 6. Toxicity classification of samples from SaiGon-DongNai basin (percentage of samples (water, aqueous and organic extracts) showing a toxicity for Daphnia magna, Ceriodaphnia cornuta or Vibrio fischeri according to the classification described in [23])
[3] M.T. Anh, L.M. Triet, 'Annual Reports: Environmental Monitoring of HCMC and Mekong Delta', HCMC, 1996-2002.

[4] L.M. Triet, N.T. Hung, M.T. Anh, 'Final Report: SaiGon-DongNai River Basin Environmental Project', National Project, HCMC, 2003.

[5] Environmental Committee of HCMC (ENCO), Final Report on Water Quality Monitoring Program from 9/2001 to 9/2002, HCMC, 2002.

[6] Environmental Protection Center (EPC), 'Report on Water Quality of Downstream DongNai River-UNDP Project, DongNai', 1998.

[7] APHA (American Public Health Association), 'Standard Methods for the Examination of Water and Wastewater', Washington DC., 1998.

[8] ASTM (American Society for Testing and Materials on aquatic toxicology and hazard evaluation), E-47, 1993, 468-476.

[9] L.C. Do Hong, K. Becker-van Slooten, J.J. Sauvain, M.T. Lam, J. Tarradellas, Environ. Toxicol. 2000, 15(5), 469-475.

[10] S.L. Smith, D.D. MacDonald, K.A. Keenleyside, J. Great Lakes Res. 1996, 22(3), 624-638.

[11] E.R. Long, D.D. MacDonald, Human and Ecological Risk Assessment 1998, 4(5), 1019-1039.

[12] E.R. Long, C.J. Wilson, Marine Pollution Bulletin 1997, 34(6), 373-374.

[13] CCME (Canadian Council of Ministers of the Environment), Canadian Sediment Quality Guidelines for the Protection of Aquatic Life, 2002.

[14] UNU-VASS, International Symposium on Endocrine - Disrupting Chemical Symposium Proceedings, HaNoi, 2002.

[15] L.L. McConnell, J.S. LeNoir, S.D., and J.N. Seiber, Environ. Toxicol. and Chem. 1998, 17, 1908-1996.

[16] E.R. Long, D.D. MacDonald, S.L. Smith, F.D. Calder, Environmental Management 1995, 19(1), 81-97.

[17] E.R. Long, L.J. Field, D.D. MacDonald, Environ. Toxicol. and Chem. 1998a, 17(4).

[18] E.R. Long, D.D. MacDonald, J. Cubbage, C.G. Ingersoll. Environ. Toxicol. and Chem. 1998b, 17(5).

[19] D.D. MacDonald, R.S. Carr, F.D. Calder, E.R. Long, C.G. Ingersoll, Ecotoxicology 1996, 5, 253-278.

[20] W. Ahlf, H.Hollert, H.N-.Hensel, M. Ricking, J. Soils \& Sediments 2002, 2(1), $37-42$.

[21] P.K. Phuong, C.P.N. Son, J.J-. Sauvain, J. Tarradellas, Bull. Environ. Contam. Toxicol. 1998, 60, 347-354

[22] L.C. Do Hong, K. Becker-van Slooten, J.J.- Sauvain, M.T. Lam, J. Tarradellas, Environ. Toxicol. 2000, 15(5), 469-475.

[23] L.C. Do Hong, Development and validation of a bioassay for the ecotoxicological risk assessment of tropical fresh water systems, PhD dissertation N. 2520, Ecole polytechnique fédérale de Lausanne, Switzerland, 2002. 